\title{
High light bio-fortification stimulates de novo synthesis of resveratrol in Diplotaxis tenuifolia (wild rocket) micro-greens
}

\author{
Bianke Loedolff $^{1 *}$, Jolene Brooks ${ }^{1}$, Marietjie Stander², Shaun Peters ${ }^{1}$, and Jens \\ Kossmann ${ }^{1}$
}

\begin{abstract}
${ }^{1}$ Institute for Plant Biotechnology, Department of Genetics, Faculty of AgriSciences, Stellenbosch University, Matieland, 7602, South Africa; ${ }^{2}$ Central Analytical Facilities, Stellenbosch University, Matieland, 7602, South Africa
\end{abstract}

*Corresponding author: Bianke Loedolff, PhD, Institute for Plant Biotechnology, Department of Genetics, Stellenbosch University, Matieland, 7602, South Africa

Submission Date: July 30th, 2017, Acceptance Date: November 27th:, 2017, Publication Date: November 30th, 2017

Citation: Loedolff B., Brooks J., Stander M., Peters S., Kossmann J., High light bio-fortification stimulates de novo synthesis of resveratrol in Diplotaxis tenuifolia (wild rocket) micro-greens. Functional Foods in Health and Disease 2017; 7(11), 859-872. https://doi.org/10.31989/ffhd.v7i11.380

\begin{abstract}
Background: Brassica vegetables and leafy greens are consumed globally due to their health promoting phytochemicals. Diplotaxis tenuifolia (wild rocket or arugula) is a popular Brassica leafy green, with a diverse range of phytochemicals (in mature plants). Immature plants (micro-greens, 2-4 true leaves) accumulate phytochemicals up to 10 times more than plants grown to maturity. Although plants accumulate phytochemicals ubiquitously, environmental stimuli can further enhance this phenomenon of accumulation, which is part of a global stress mechanism in plants. In this study, we describe a simple method toward the bio-fortification of a wild rocket micro-green system, via environmental manipulation (using high light).
\end{abstract}

Objective: To establish a high light-induced bio-fortification strategy to augment the accumulation of bio-active compounds in Brassica micro-greens (wild rocket), with the purpose of developing a 'designer' micro-green melange (functional food product) containing a diverse range of bio-active (disease preventative) compounds.

Results: High light stimulated wild rocket micro-greens to achieve a significant increase of known phytochemicals (documented in relevant Brassica leafy greens). Furthermore, undocumented phytochemicals (resveratrol, catechin, epicatechin, and kaempferol, among others) also accumulated to adequate concentrations. Plant extracts from bio-fortified micro-greens displayed increased antioxidant capacity (up to 3-fold, when compared to the control), a key component in future cancer cell research. 
Conclusion: The use of high light resulted in successful bio-fortification of wild rocket micro-greens, evidenced by the accumulation of previously undocumented polyphenols (such as resveratrol, catechin and epicatechin) and improved antioxidant capacity.

Keywords: antioxidant, high light, micro-greens, resveratrol, wild rocket

\section{INTRODUCTION}

Brassica vegetables and leafy greens (brussel sprouts, broccoli, kale, and watercress among others) host a broad range of phytochemicals (largely glucosinolates and polyphenolic compounds) and are consumed globally due to their association with health-promoting benefits [1-7]. Diplotaxis tenuifolia (wild rocket or arugula) is a popular Brassica leafy green, originating from the Mediterranean but consumed globally (mostly raw as a salad addition), due to its aroma and pungent taste [8]. Recently, there has been an increasing interest in phytochemical profiling of wild rocket species (Eruca sativa and D. tenuifolia, in addition to subsequent breeding varieties), describing an array of health beneficial compounds including glucosinolates (implicated in the pungent taste), flavonols, polyphenolics, vitamins, and nitrates [9-16]. Polyphenolics (flavonones) like quercetin (and its derivatives, most prominent in Diplotaxis spp.) and kaempferol (and its derivatives, most prominent in Eruca spp.) form the core phenolic backbones in rocket species [11, 17].

Although plants accumulate phytochemicals ubiquitously, micro-greens (immature plants with 2-4 true leaves) are considered nutritionally superior as they hyper-accumulate phytochemicals (up to 10 times more than mature counterparts [18]. Recent studies have demonstrated that wild rocket is highly nutritious; however, most of these studies mainly focused on the mature rocket plant [16, 19-21]. Few studies have been conducted on D. tenuifolia micro-greens, all of which primarily investigated the effects of commercial storage on phytochemical stability and retention [20, 22].

Phytochemical accumulation in plants has been shown to accumulate as part of a global stress response mechanism and can thereby be further enhanced when environmental stress factors (light, temperature, salinity, and water deficit) are applied [23]. Through exploiting and applying this knowledge on wild rocket micro-greens, we observed consistent high light-induced de novo synthesis of the sought-after polyphenol, resveratrol (largely implicated for its role in cardiovascular-related disease prevention). This was equally accompanied by mass increases of other health-beneficial phytochemicals previously documented/undocumented in rocket species (kaempferol, quercetin, isorhamnetin, catechin, and epicatechin). To our knowledge, this is the first report exploiting the phenylpropanoid pathway in wild rocket micro-greens to accumulate a more diverse range of phytochemicals (resveratrol, catechin, epicatechin, kaempferol, and quercetin) using high light. We further described physiologically relevant antioxidant assays to determine the possibility of using high light bio-fortified micro-greens as a functional food, which could be consumed as part of a daily diet.

\section{MATERIALS AND METHODS}

\section{Plant material and growth conditions}

Diplotaxis tenuifolia (wild rocket) seeds were obtained from a commercial nursery (Starke Ayres $^{\mathrm{TM}}$, Stodels Garden Centre, Kenilworth, South Africa). Subsequent to stratification $\left(24 \mathrm{~h}, 4{ }^{0} \mathrm{C}\right.$ ), wild rocket plants were propagated to the micro-green stage (two true leaves) 
under (i) controlled growth conditions (16 h light, $72 \mu \mathrm{mol}$ photons $\mathrm{m}^{-2} \mathrm{~s}^{-1}, 22{ }^{0} \mathrm{C}, 8 \mathrm{~h}$ dark, $22{ }^{0} \mathrm{C}, 60 \%$ relative humidity) and (ii) high light intensity $\left(272 \mu \mathrm{mol}\right.$ photons $\left.\mathrm{m}^{-2} \mathrm{~s}^{-1}\right)$. All plants were maintained and propagated on peat disks (Jiffy ${ }^{\mathrm{TM}}$ no.7, South Africa) and supplemented with 0.14\% (w/v) Phostrogen (Bayer, Stark Ayres ${ }^{\circledR}$ Garden Center, Cape Town, South Africa), at 7 and 21 days post germination as previously described [24].

\section{Metabolite extractions}

Total anthocyanins and chlorophyll were extracted from whole wild rocket micro-greens (100 and $8 \mathrm{mg}$ fresh weight respectively) and measured spectrophotometrically, as previously described [25, 26]. Independent experiments were performed in triplicate, using pooled samples of micro-greens (approximately 200 plants per replicate).

Polyphenols were extracted from whole wild rocket micro-greens $(300 \mathrm{mg}$ ), as previously described [27], with the addition of paracetamol $\left(0.1 \mathrm{mg} \mathrm{ml}^{-1}\right)$ as an internal standard. Prior to LC-MS/MS analysis, sample extracts were lyophilized and desalted as previously described (omitting the Polyklar AT; [28]).

\section{Ascorbic acid and antioxidant activity assays}

Ascorbic acid was quantified in fresh, macerated rocket micro-green tissue (500 mg) using a commercially available kit (Cat. \# MAK074, Sigma-Aldrich, South Africa), according to manufacturer's instructions. Similarly, total antioxidant capacity was determined in either fresh or lyophilised, macerated rocket micro-green tissue $(500 \mathrm{mg})$ as compared against a Trolox standard, using a commercially available kit (Cat. \# MAK187, Sigma-Aldrich, South Africa), according to manufacturer's instructions.

\section{LC-MS/MS analyses, phenolic compound identification and quantification}

LC-MS/MS analyses were performed with a Waters Synapt G2 quadrupole time-of-flight mass spectrometer (Waters Corporation, Milford, MA, USA) equipped with a Waters Acquity UPLC. Samples were separated on a Waters UPLC BEH C18 column $(2.1$ x 100 $\mathrm{mm} ; 1.7 \mu \mathrm{m}$ ) at a flow rate of $0.3 \mathrm{ml} / \mathrm{min}$ at $55{ }^{\circ} \mathrm{C}$. Solvent A consisted of $0.1 \%$ formic acid in water and solvent $\mathrm{B}$ was $0.1 \%$ formic acid in acetonitrile. The mobile phase gradient was initiated at $100 \%$ solvent A for 1 min and linearly reduced to $28 \%$ solvent A over 22 min. Subsequently, the mobile phase was changed to $40 \%$ solvent B over $50 \mathrm{~s}$ followed by a wash step in $100 \%$ solvent B before the column was re-equilibrated to the initial conditions for $4 \mathrm{~min}$. Electrospray ionization was applied in the negative mode and the scan range was either from $\mathrm{m} / \mathrm{z}$ 150-1500 (high collision energy scan) or from $\mathrm{m} / \mathrm{z}$ 40-1500 (low collision energy scan). The photo diode array detector was set to scan from 220-600 nm. The capillary voltage was set at either $6 \mathrm{~V}$ (low collision energy scan from) or 30-60 V (high collision energy scan), the cone voltage was $15 \mathrm{~V}$, the source temperature $120{ }^{\circ} \mathrm{C}$ and the desolvation temperature was $275{ }^{\circ} \mathrm{C}$. The desolvation and cone gas (nitrogen) flows were $650 \mathrm{~L} / \mathrm{h}$ and 50 $\mathrm{L} / \mathrm{h}$ respectively. Sodium formate was used for calibration and leucine encephalin was infused in the background as lock mass for accurate mass determinations. Metabolite quantifications (where applicable) were conducted against a series of standard flavonoids (proanthocyanidin, isorhamnetin, sinigrin, myricetin, catechin, resveratrol, kaempferol, and epicatechin at a concentration of $0.1 \mathrm{mg} \mathrm{ml}^{-1}$ ), and metabolite recovery was monitored with the internal standard (paracetamol, $0.1 \mathrm{mg} \mathrm{ml}^{-1}$ ). Metabolites were monitored using their 
deprotonated quasi-molecular ions and quantified or identified (where possible) with the TargetLynx application manager (Waters MassLynx V4.1V software). Tentative identification was based on the accurate mass, fragment ions, and UV spectra of the specific peaks compared to literature.

\section{Data and statistical analyses}

All data acquired for chlorophyll, anthocyanin, ascorbic acid, and total antioxidant capacity measurements are expressed as means \pm standard error of at least three independent experiments. Statistical significance was determined by a two tailed t-test $(p<0.05)$, using the control group (normal light) as a comparison. Statistical analysis was performed with GraphPad Prism 7.0. All LC-MS/MS metabolites, where applicable (identified) were quantified against a set of commercial standards $\left(0.1 \mathrm{mg} \mathrm{ml}^{-1}\right.$ concentrations were injected for all standards) using the TargetLynx application manager software. Three independent LC-MS/MS experiments were conducted and the average was calculated for each compound identified.

\section{RESULTS}

High light increases anthocyanin and chlorophyll content in in D. tenuifolia micro-greens Chlorophyll and anthocyanin accumulation were measured from freshly harvested D. tenuifolia (wild rocket) micro-greens propagated under normal light (NL) and high light (HL) conditions, using a standard spectrophotometric platform. Unexpectedly, wild rocket micro-greens indicated no significant change in chlorophyll accumulation $\left(0.168 \pm 0.09 \mu \mathrm{g} \mathrm{g}^{-1} \mathrm{FW}\right.$ and $0.185 \pm 0.08 \mu \mathrm{g} \mathrm{g}^{-1} \mathrm{FW}$ for NL and HL respectively; Figure 1A). However, wild rocket micro-greens accumulated anthocyanins approximately 2-fold higher under HL conditions $\left(2.17 \pm 0.09 \mu \mathrm{g} \mathrm{g}^{-1} \mathrm{FW}\right.$ and $4.16 \pm 0.08 \mu \mathrm{g} \mathrm{g}^{-1} \mathrm{FW}$ for NL and HL respectively; Figure 1B).
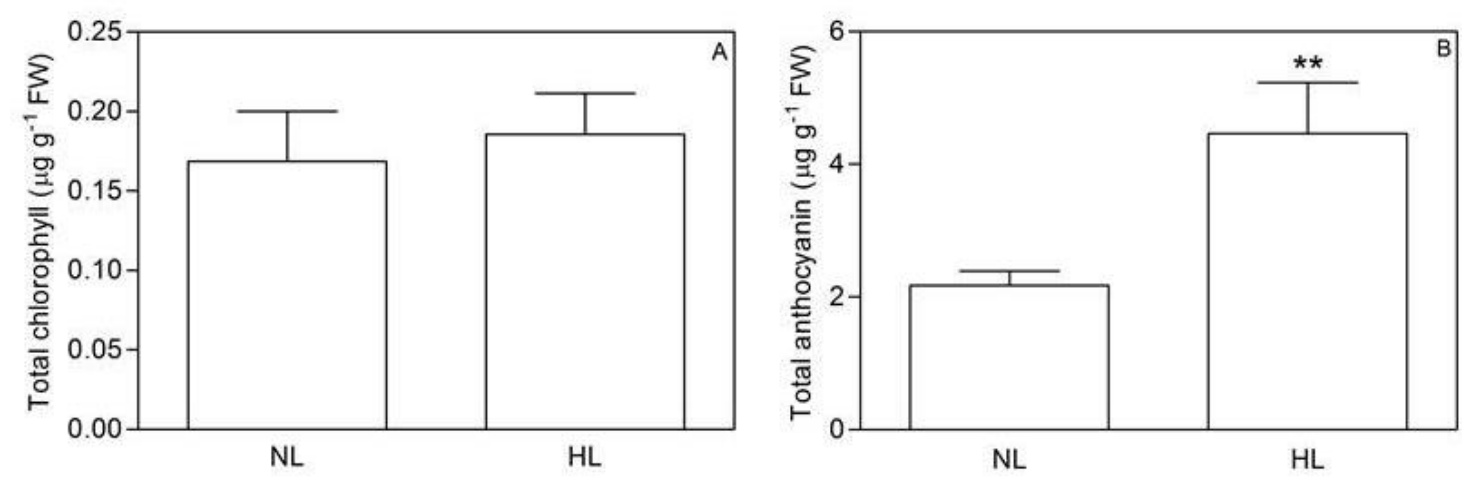

Figure 1. Spectrophotometric analyses of (A) chlorophyll and (B) anthocyanin accumulation. Fresh plant material was harvested from wild rocket micro-greens propagated under normal and high light conditions. Subsequently, chlorophyll and anthocyanin accumulation were measured respectively, from three independent experiments, using pooled samples of micro-greens (approximately 200 plants per replicate). Statistical significance is indicated by stars as determined by a two tailed t-test, using NL as the comparison control (B; HL **p $\leq$ 0.0022). NL, normal light; HL, high light; FW, fresh weight. 
High light improves ascorbic acid accumulation and antioxidant capacity in D. tenuifolia micro-greens

Ascorbic acid (vitamin C) content was measured in fresh wild rocket micro-green tissue. Ascorbic acid content increased significantly in fresh wild rocket micro-green tissue, almost 2-fold higher, under HL when compared to NL conditions $\left(0.9 \pm 0.06 \mathrm{mg}^{-1}\right.$ and

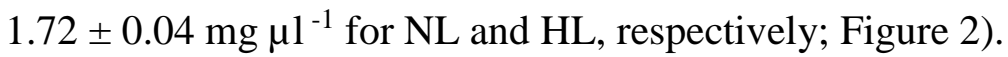

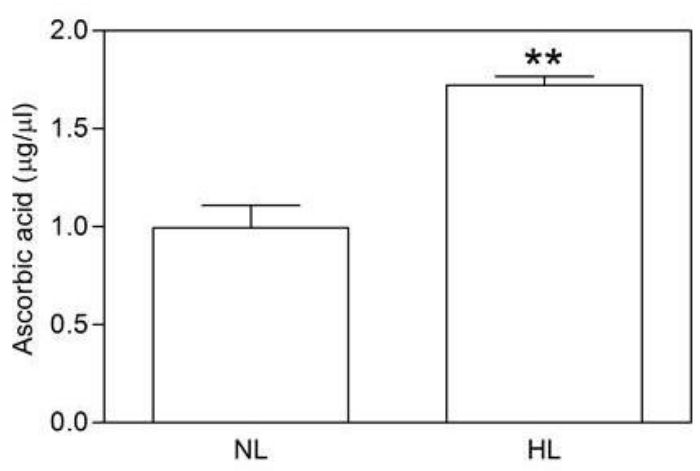

Figure 2. Accumulation of ascorbic acid in bio-fortified wild rocket. Fresh plant material was harvested from wild rocket micro-greens propagated under normal and high light conditions, respectively. Subsequently, ascorbic acid was determined from three independent experiments, using pooled samples of micro-greens (approximately 200 plants per replicate). Statistical significance is indicated by stars as determined by a two tailed t-test, using NL as the comparison control ( $\left.\mathrm{HL}^{* *} \mathrm{p} \leq 0.0022\right)$. NL, normal light; HL, high light.

Wild rocket micro-greens (freshly macerated) were further analyzed for their antioxidant capacity using a Trolox (vitamin E equivalent) comparison. Using a commercial kit, the $\mathrm{Cu}^{+}$-reducing (antioxidant) capacity was analyzed and values provided as Trolox equivalents. Antioxidant capacity increased significantly in fresh wild rocket micro-greens, being almost 2.7-fold higher under HL when compared to NL conditions $\left(94.4 \pm 9.4 \mathrm{nmol} \mu \mathrm{l}^{-1}\right.$ and 260.96 $\pm 10.82 \mathrm{nmol} \mu 1^{-1}$ Trolox equivalent for NL and HL respectively; Figure 3).

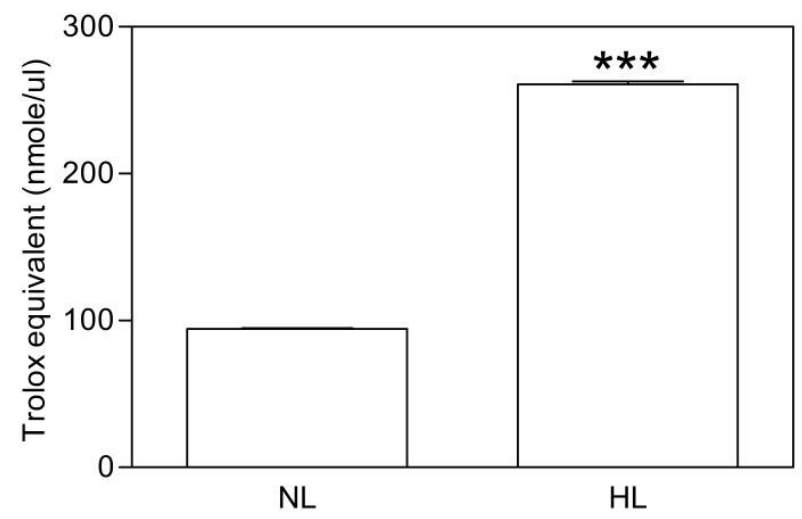

Figure 3. Antioxidant capacity of bio-fortified wild rocket. Fresh plant material was harvested from wild rocket micro-greens propagated under normal and high light conditions, respectively. Subsequently, antioxidant capacity was determined, using the CUPRAC method, from three independent experiments, using pooled samples of micro-greens (approximately 200 plants per replicate). Statistical significance is indicated by stars as determined by a two tailed t-test, using NL as the comparison control ( $\left.\mathrm{HL}^{* * *} \mathrm{p} \leq 0.0055\right)$. NL, normal light; HL, high light. 
LC-MS analyses reveal mass increases of previously documented and undocumented polyphenolic compounds in D. tenuifolia micro-greens grown under high light

Quantitative LC-MS/MS was conducted to identify compounds or to determine the mass increases of (i) anthocyanins and (ii) polyphenolic compounds in wild rocket micro-greens, using a range of commercially available standards. In contrast to the spectrophotometric analyses (described in section 1.3.1), no anthocyanins were detected using LC-MS/MS UV-analyses (data not shown). Wild rocket micro-greens grown under NL conditions accumulated high amounts of quercetin and isorhamnetin (approximately $0.0036 \mathrm{nmol}^{-1}$ and $0.007 \mathrm{nmol} \mu \mathrm{l}^{-1}$ respectively; Table 1). Wild rocket micro-greens grown under HL conditions accumulated quercetin and isorhamnetin concentrations of approximately 2- and

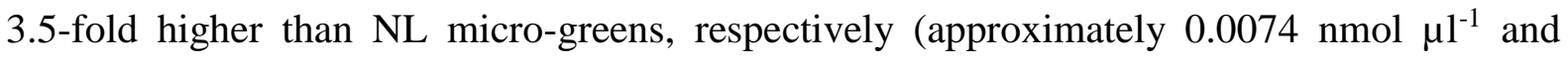
$0.025 \mathrm{nmol} \mathrm{l}^{-1}$ respectively; Table 1 ).

Table 1. Polyphenolic compounds accumulating in bio-fortified wild rocket. Quantitative LC-MS/MS was conducted to identify novel compounds or to determine the mass increases of quantifiable polyphenolic compounds in wild rocket micro-greens, using a range of commercially available standards (proanthocyanidin, isorhamnetin, sinigrin, myricetin, catechin, resveratrol, kaempferol, and epicatechin). Concentrations were calculated as an average, using three independent experiments (approximately 200 micro-greens each round). The mass spectra ( $\mathrm{m} / \mathrm{z}$ ratio) of each peak correlating to the commercial standards were extracted from the total ion chromatogram, confirming the identity of each polyphenolic compound in the micro-green extracts and subsequently quantified against a known amount of standard compound.

\begin{tabular}{llll}
\hline Compound (commercial standard) & Normal light & High light & Fold change \\
& (nmol/ul) & (nmol/ul) & \\
\hline Catechin & n. d & 0.003828 & \\
\hline Quercetin & 0.003676 & 0.007353 & 2 \\
\hline Kaempferol-3d-glucoside & n. d & 0.002478 & \\
\hline Epicatechin & n. d & 0.007656 & \\
\hline Myricetin & n. d & 0.006983 \\
\hline Isorhamnetin & & & \\
\hline ProcyanidinB & 0.007027 & 0.024593 \\
\hline Resveratrol & n. d & n. d & \\
\hline
\end{tabular}

* n. d - not detected 
Furthermore, HL grown micro-greens also accumulated a range of alternative polyphenolic compounds (catechin, kaempferol-3d-glucoside, epicatechin, myricetin, quercetin-3-

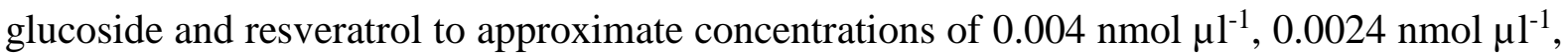
$0.008 \mathrm{nmol} \mu \mathrm{l}^{-1}, 0.007 \mathrm{nmol} \mu \mathrm{l}^{-1}$ and $0.0024 \mathrm{nmol} \mu \mathrm{l}^{-1}, 0.024 \mathrm{nmol} \mu \mathrm{l}^{-1}$, respectively; Table 1). Further analyses were conducted with LC-MS/MS data to certify the de novo synthesis of resveratrol. The mass spectrum $(\mathrm{m} / \mathrm{z}$ ratio) of the peak, correlating to the commercial resveratrol standard, was extracted from the total ion chromatogram, confirming the identity of resveratrol in the micro-green extracts (Figure 4).
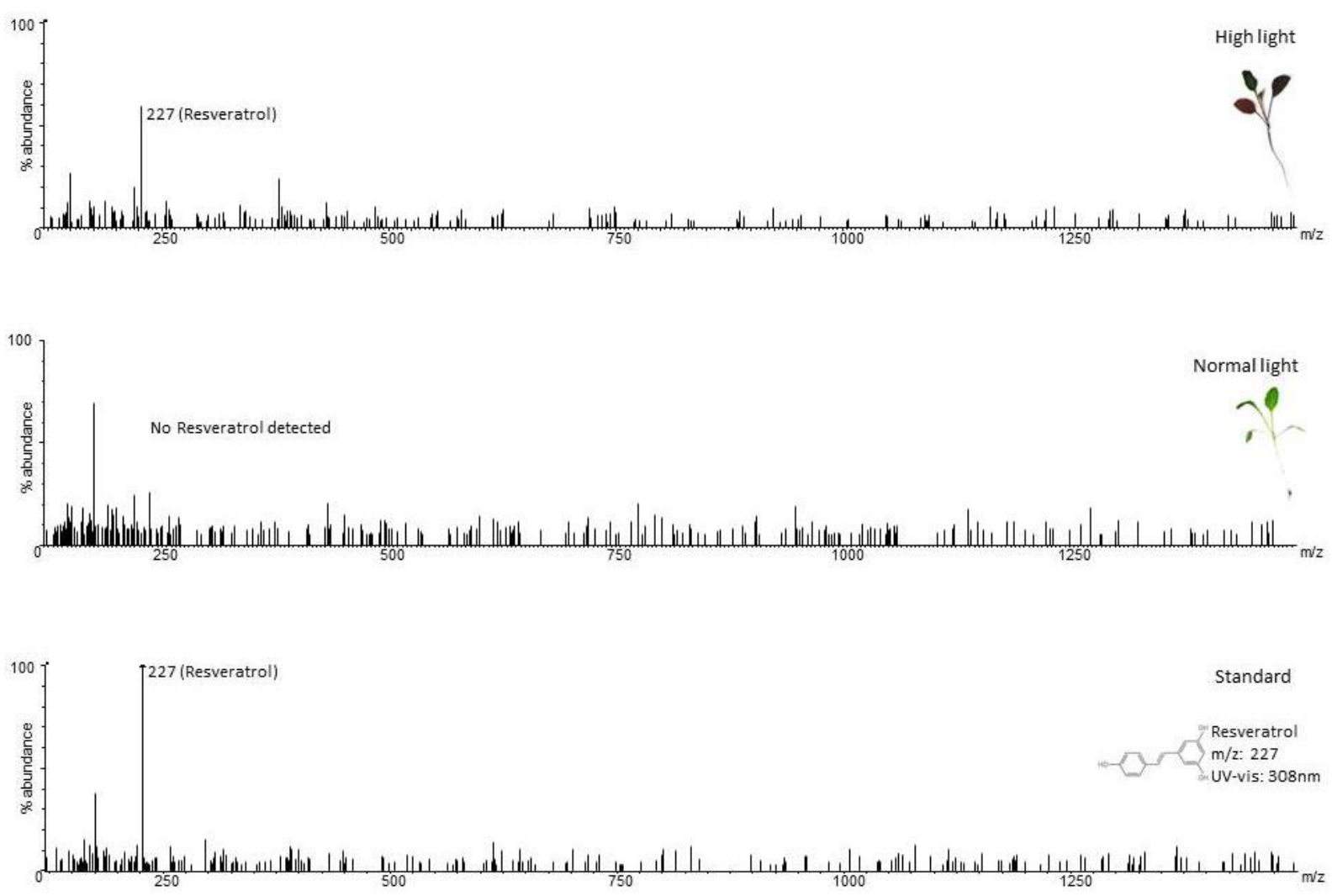

Figure 4. Resveratrol accumulates in bio-fortified wild rocket micro-greens. Metabolites were monitored using their deprotonated quasi-molecular ions for specific identification of compounds. The MS/MS spectrum of corresponding resveratrol peak, indicating the deprotonated state (1-) at a $\mathrm{m} / \mathrm{z}$ of 227 . Polyphenolics extracted from wild rocket micro-greens, propagated under normal (top panel) and high (middle panel) light conditions. Polyphenolics extracted from bio-fortified (high light induced) wild rocket micro-greens unequivocally accumulated resveratrol (bottom panel).

\section{DISCUSSION}

Recent societal health awareness among populations globally has stimulated research efforts to venture into plant-based fortification strategies resulting in products (functional foods) with improved health benefits. Although mature Brassica species (broccoli, kale, and brussel sprouts among others) has been well described to accumulate a diverse array of phytochemicals (and potentially play a role in the prevention of non-communicable diseases), a sustained diet (Brassica-enriched) is required for health beneficial effects [29, 30]. In contrast, immature plants (grown to micro-green stage, with 2-4 true leaves) accumulate significantly higher amounts of phytochemicals (up to 10 times more than plants grown to 
maturity), which are required as part of defense mechanisms enabling young plants to survive, mature and defend against potential environmental stresses [23]. Bio-fortification strategies to improve the accumulation of health beneficial compounds are becoming more prevalent. Recent studies focused on the external application of selenium and zinc to enhance the accumulation of important minerals [31, 32]. Accordingly, our aim was to exploit natural environmental processes (such as high light) as a bio-fortification strategy to improve the health beneficial properties (phytochemical accumulation) of wild rocket micro-greens.

Although phytochemicals accumulate in plants ubiquitously, it has been described in numerous studies that environmental stimulus (abiotic and biotic) result in increased production of phytochemicals as part of a plant's global stress response/protection mechanism [33-35]. High light (HL) specifically induces abundant reactive oxygen species (ROS) in plants which would require the production of antioxidants to scavenge these molecules [36, 37]. Subsequent to growing wild rocket micro-greens under HL conditions (using a normal light, NL, regime as control), we observed a red coloration of the micro-greens whereas the NL stayed green (Figure 4, side panel). It is well known that this type of coloration in plants is largely due to anthocyanin accumulation, and is also popularly referred to as the 'color-pigment' in plants $[38,39]$. Chlorophyll, which is usually used as an indicator of senescence (plant related) or viability (shelf-life), has been described to concomitantly decrease as anthocyanin content increases, when plants are exposed to environmental stresses [40-43]. Therefore, we aimed to investigate whether this phenomenon also holds true for the wild rocket micro-green system.

Surprisingly, there was no difference in the accumulation of chlorophyll between NL and HL micro-greens (Figure 1A), which we attribute to the unique photosynthetic mechanism (enhanced carbon fixation via $\mathrm{C} 3-\mathrm{C} 4$ intermediate photosynthetic pathway) of rocket plants $[44,45]$. We propose that this could certainly be used as a strong viability determinant during storage conditions in fresh micro-greens. Furthermore, anthocyanins (part of a polyphenol subgroup termed flavonoids), which are often reported for their role as a radical scavenger in humans and plants [46-48], has only been reported to occur in the flowers of Eruca sativa and not in any other organ among the collective of rocket species [49]. Initial anthocyanin accumulation, in NL and HL wild rocket micro-greens, was investigated via a classic spectrophotometric method as previously described [25, 26]. According to this method, anthocyanin content increased under HL conditions (initial explanation for the observed red coloration, Figure 1B). However, this observation was contradicting previous literature reports. When the anthocyanin profile was investigated via LC-MS/MS (based on UV profile), none were detected (data not shown), confirming previous literature reports. We speculate that the spectrophotometric method also detects the parent group of anthocyanins, polyphenols, which could result in biased experimental outcomes and propose that high-throughput technologies (such as LC-MS/MS) should be relied on for accurate phenolic content measurements and compound identification. Subsequently, we analyzed the polyphenol content in the micro-greens via LC-MS/MS to determine the effects of HL on health beneficial phytochemical accumulation, and to potentially unravel a compound responsible for the red phenotype observed in the HL grown micro-greens. A range of commercially available compounds (among them were compounds known to accumulate in mature rocket leaves, such as quercetin and kaempferol, which form the polyphenolic backbone of rocket species) were used to quantify the accumulation of well-known compounds in the phenylpropanoid biosynthetic pathway, in wild rocket micro-greens. 
LC-MS/MS analyses indicated that HL grown micro-greens accumulated both novel and mass increases of known polyphenols, especially quercetin (in both NL and HL micro-greens) which was previously reported as a major polyphenol in wild rocket (specifically D. tenuifolia [11, 17]). HL conditions not only favored the mass increase of quercetin compounds (Table 1), but also stimulated the accumulation of a range of other polyphenolic compounds (either as aglycones or glucosides) which could be categorized as a (i) flavonol (such as kaempferol, mostly known to occur in E. sativa species), (ii) flavan-3-ol (catechin and epicatechin), and (iii) stilbene (resveratrol). The latter compounds have not been reported before to accumulate in wild rocket micro-greens, but are respectively major health beneficial compounds in green and black tea, in addition to peanut and grape-skins $[50,51]$. One possible suggestion is that the development of red coloration could be due to the accumulation of resveratrol (given the absence of anthocyanins), which in its native form displays a red color (as in red cabbage, peanut, and grape skins). Among the polyphenolic compounds identified, resveratrol is probably considered the most popular (due to the "French paradox" [52]) and has been described as a cardiovascular protective agent, displays both in vitro and in vivo antioxidant capacity [53-55], and chemoprotective properties (at concentrations as low as $0.001 \mathrm{nmol} / \mu \mathrm{l}[56,57]$ ). Despite multiple (often contradictory) reports regarding the poor bio-availability of resveratrol when administered as a single compound, it has been demonstrated in vivo that the co-administration of resveratrol with other phytochemicals (such as piperine, quercetin, and catechin) greatly improves the absorption into the human body [58, 59]. We obtained significant concentrations of resveratrol, quercetin, and catechin in HL grown rocket micro-greens (Table 1), which is a very promising and attractive value addition to bio-fortified functional food/food products (beyond basic human nutrition) given that these phytochemicals function synergistically to impart human health benefits. Further in vivo studies will be required to fully understand the synergistic regulation displayed by the various phytochemicals and its individual and collective influence resulting in improved bio-availability.

For the micro-green system to be validated as a potential functional food, it has to display health beneficial characteristics for humans. One of the most favorable characteristics is the ability of foods/food products to contribute antioxidant (ROS scavenging) capacities, apart from merely accumulating health beneficial polyphenolic compounds. Ascorbic acid (vitamin C) has been reported as the most abundant vitamin to accumulate in wild rocket [60]. It is known for its ability to act as a ROS scavenger in vivo, and even fulfills this role in plants to some extend [61-63]. We analyzed the vitamin $\mathrm{C}$ content in fresh NL and HL micro-greens and found mass increases in HL micro-greens which could be a beneficial contributing factor during ROS scavenging for the plant itself (Figure 2A). We further analyzed physiologically relevant (neutral $\mathrm{pH}$ ) antioxidant capacity in the micro-green system, using a cupric ion reducing method (CUPRAC [64]), to determine this characteristic potential of NL and HL grown wild rocket micro-greens. Both vitamin $\mathrm{C}$ and other polyphenolics, such as resveratrol (also a strong ROS scavenger), would attribute to antioxidant capacity and we therefore investigated the micro-greens as a fresh product, based on human consumption (raw in salads). Even though the NL micro-greens indicated a potentially viable antioxidant capacity (Figure 3A), no resveratrol accumulated under these conditions. HL micro-greens indicated a significantly improved antioxidant capacity (Figure $3 \mathrm{~A}$ ), and we attribute this to the abundant accumulation of health beneficial polyphenolic compounds (Table 1). However, we also emphasize the non-nutritive (beyond basic nutrition) benefits of resveratrol, and in this case as one of the potential phytochemical candidates in 
non-communicable disease prevention strategies, a novel value addition to HL-induced biofortification of wild rocket micro-greens.

\section{CONCLUSION}

Micro-greens have garnered increasing support to enter into the commercial market, apart from sprouts (germinated seedlings, with only cotyledons). Interestingly, sprouts are losing popularity amongst commercial users due to consistent pathogenic bacterial contamination issues. Concurrently, the FDA recalled a number of sprout products (alfalfa, soybean, and green onions) and warnings released by the FDA deemed these germinated seeds as unsafe for human consumption (https://www.fda.gov/Safety/Recalls/ucm562449.htm). Thus, our research efforts focus on the development of bio-fortified (further enhancing phytochemical content) micro-green systems using environmental stimuli, which is safe for human consumption as a part of a daily diet. We applied environmental high-light stimulus with the aim of enhancing phytochemical profiles in D. tenuifolia (wild rocket) micro-greens. Thus far we have successfully demonstrated the following outcomes: (i) unambiguous increases in polyphenolic content by high light-stimulation, (ii) accumulation of previously undocumented polyphenolics, and (iii) consequent increases in antioxidant capacity. To our knowledge this is the first report indicating the de novo synthesis of (i) resveratrol, (ii) catechin, and (iii) epi-catechin compounds in a wild rocket (specifically D. tenuifolia) micro-green system, all of which have been previously described to significantly contribute to human health and well-being. We propose that such a system of bio-fortification of various micro-greens could be successfully used as an enriched supplement (functional food) as part of preventative measures against non-communicable diseases. Consequently, we are currently investigating the effects of lyophilized extracts from bio-fortified wild rocket micro-greens in vitro on a range of non-communicable diseases (ie. cancer cell lines).

List of Abbreviations: CUPRAC, CUPric Reducing Antioxidant Capacity; FDA, Food and Drug Administration; FW, Fresh Weight; HL, High Light; LC-MS, Liquid Chromatography Mass Spectrometry; $m / z$, mass to charge ratio; NL, Normal Light; ROS, Reactive Oxygen Species; UV, Ultra Violet

Competing Interests: The authors declare no conflicts of interest.

Author Contribution: BL conceived, designed, executed and analysed data regarding the project. BL wrote the manuscript. JB obtained BSc Hons (4th semester undergraduate) degree working on partial areas of the project. MS executed LC-MS/MS runs. SP provided valuable insight and experimental advice that furthered the outcomes of the study. JK provided resources, funding and insight toward the project.

Acknowledgments and Funding: The authors would like to acknowledge the South African National Research Foundation and the Department of Science and Technology for financial contribution.

\section{REFERENCES}

1. Verhoeven DT, Goldbohm RA, van Poppel G, Verhagen H, van den Brandt PA: Epidemiological studies on Brassica vegetables and cancer risk. Cancer Epidemiol Biomarkers Prev 1996, 9:733. 
2. Doostdar H, Burke MD, Mayer RT: Bioflavonoids: selective substrates and inhibitors for cytochrome P450 CYP1A and CYP1B1. Toxicol 2000, 144:31-38.

3. Rose P, Faulkner K, Williamson G, Mithen R: 7-Methylsulfinylheptyl and 8methylsulfinyloctyl isothiocyanates from watercress are potent inducers of phase II enzymes. Carcinogen 2000, 21:1983-1988.

4. Fahey JW, Haristoy X, Dolan PM, Kensler TW, Scholtus I, Stephenson KK, Talalay P, Lozniewski A: Sulforaphane inhibits extracellular, intracellular, and antibioticresistant strains of Helicobacter pylori and prevents benzo[alpha]pyrene-induced stomach tumors. Proc Natl Acad Sci 2002, 99:7610-7615.

5. Boyd LA, McCann MJ, Hashim Y, Bennett RN, Gill CIR, Rowland IR: Assessment of the anti-genotoxic, anti-proliferative, and anti-metastatic potential of crude watercress extract in human colon cancer cells. Nutr Cancer 2006, 55:232-241.

6. Gill CI, Haldar S, Boyd LA, Bennett R, Whiteford J, Butler M, Pearson JR, Bradbury I, Rowland IR: Watercress supplementation in diet reduces lymphocyte DNA damage and alters blood antioxidant status in healthy adults. Am J Clin Nut 2007, 85:504-10.

7. Bell L, Wagstaff C: Glucosinolates, Myrosinase Hydrolysis Products, and Flavonols Found in Rocket (Eruca sativa and Diplotaxis tenuifolia). J Agric Food Chem 2014, 62:4481-4492.

8. Bennett RN, Carvalho R, Mellon FA, Eagles J, Rosa EAS: Identification and quantification of glucosinolates in sprouts derived from seeds of wild Eruca sativa $L$. (Salad Rocket) and Diplotaxis tenuifolia L. (Wild Rocket) from diverse geographical locations. J Agric Food Chem 2007, 55:67-74.

9. Heaney RK, Fenwick GR: Natural toxins and protective factors in brassica species, including rapeseed. Nat Toxins 1995, 3:233-237.

10. Nestle M, Wing R, Birch L, DiSogra L, Drewnowski A, Middleton S, Sigman-Grant M, Sobal J, Winston M, Economos C: Behavioral and social Influences on food choice. Nut Rev 1998, 56:50-64.

11. Bennett RN, Rosa EAS, Mellon FA, Kroon PA: Ontogenic Profiling of Glucosinolates, Flavonoids, and other secondary metabolites in Eruca sativa (Salad Rocket), Diplotaxis erucoides (Wall Rocket), Diplotaxis tenuifolia (Wild Rocket), and Bunias orientalis (Turkish Rocket). J Agric Food Chem 2006, 54:4005-4015.

12. Vauzour D, Rodriguez-Mateos A, Corona G, Oruna-Concha MJ, Spencer JPE: Polyphenols and human health: Prevention of disease and mechanisms of action. Nutrients 2010, 2:1106.

13. Traka MH, Saha S, Huseby S, Kopriva S, Walley PG, Barker GC, Moore J, Mero G, van den Bosch F, Constant H, Kelly L, Schepers H, Boddupalli S, Mithen RF: Genetic regulation of glucoraphanin accumulation in Beneforté ${ }^{\circledR}$ broccoli. New Phytol 2013, 198: 4.

14. Bell L, Oruna-Concha MJ, Wagstaff C: Identification and quantification of glucosinolate and flavonol compounds in rocket salad (Eruca sativa, Eruca vesicaria and Diplotaxis tenuifolia) by LC-MS: Highlighting the potential for improving nutritional value of rocket crops. Food Chem 2015, 172:852-861.

15. Bell L, Spadafora ND, Müller CT, Wagstaff C, Rogers HJ: Use of TD-GC-TOF-MS to assess volatile composition during post-harvest storage in seven accessions of rocket salad (Eruca sativa). Food Chem 2016, 194:626-636. 
16. Bell L, Methven L, Signore A, Oruna-Concha MJ, Wagstaff C: Analysis of seven salad rocket (Eruca sativa) accessions: The relationships between sensory attributes and volatile and non-volatile compounds. Food Chem 2017, 218:181-191.

17. Jin J, Koroleva OA, Gibson T, Swanston J, Magan J, Zhang Y: Analysis of phytochemical composition and chemoprotective capacity of rocket (Eruca sativa and Diplotaxis tenuifolia) leafy salad following cultivation in different environments. J Agr Food Chem 2009, 57:5227-5234.

18. Xiao Z, Lester GE, Luo Y, Wang Q: Assessment of vitamin and carotenoid concentrations of emerging food products: Edible microgreens. J Agric Food Chem 2012, 60:7644-7651.

19. Verkerk R, Schreiner M, Krumbein A, Ciska E, Holst B, Rowland I, De Schrijver R, Hansen M, Gerhäuser C, Mithen R, Dekker M: Glucosinolates in Brassica vegetables: The influence of the food supply chain on intake, bioavailability and human health. Mol Nutr Food Res 2009, 53(Suppl 2):219-219.

20. Amodio ML, Derossi A, Mastrandrea L, Colelli G: A study of the estimated shelf life of fresh rocket using a non-linear model. J Food Eng 2015, 150: 19-28.

21. Spadafora ND, Amaro AL, Pereira MJ, Müller CT, Pintado M, Rogers HJ: Multi-trait analysis of post-harvest storage in rocket salad (Diplotaxis tenuifolia) links sensorial, volatile and nutritional data. Food Chem 2016, 211:114-123.

22. Tepper BJ, White EA, Koelliker Y, Lanzara C, D'Adamo P, Gasparini P: Genetic variation in taste sensitivity to 6-n-propylthiouracil and its relationship to taste perception and food selection. Ann N Y Acad Sci 2009, 1170:126-139.

23. Fennema OR: Food chemistry. New York: Marcel Dekker; 1996.

24. Petersen LN, Marineo S, Mandala S, Davids F, Sewell BT, Ingle RA: The missing link in plant histidine biosynthesis: Arabidopsis myoinositol monophosphatase-like2 encodes a functional histidinol-phosphate phosphatase. Plant Phys 2010, 152:11861196.

25. Porra RJ, Thompson WA, Kriedmann PA: Determination of accurate extinction coefficients and simultaneous equations for assaying chlorophylls a and b extracted with four solvents: verification of the concentration of chlorophyll standards by atomic absorption spectroscopy. Biochim Biophys Acta 1989, 975:384-394.

26. Neff MM, Chory J: Genetic interactions between phytochrome A, phytochrome B, and cryptochrome 1 during Arabidopsis development. Plant Phys 1998, 118:27-35.

27. Routaboul JM, Kerhoas L, Debeaujon I, Pourcel L, Caboche M, Einhorn J, Lepiniec L: Flavonoid diversity and biosynthesis in seed of Arabidopsis thaliana. Planta 2006, 224:96-107.

28. Peters S, Mundree SG, Thomson JA, Farrant JM, Keller F: Protection mechanisms in the resurrection plant Xerophyta viscosa (Baker): both sucrose and raffinose family oligosaccharides (RFOs) accumulate in leaves in response to water deficit. J Exp Bot 2007, 58:1947-1956.

29. Johnson IT: Glucosinolates: Bioavailability and importance to health. Int J Vitam Nut Res 2002, 72:26-31.

30. Kellingray L, Tapp HS, Saha S, Doleman JF, Narbad A, Mithen RF: Consumption of a diet rich in Brassica vegetables is associated with a reduced abundance of sulphatereducing bacteria: A randomised crossover study. Mol Nut Food Res 2017, 1600992 
31. Chomchan R, Siripongvutikorn S, Puttarak P: Selenium bio-fortification: an alternative to improve phytochemicals and bioactivities of plant foods. FFHD J 2017, 7:263-279.

32. Srirattanakul T, Siripongvutikorn S, Sae-Wong C: Increasing of bioactive compounds in Mentha cordifolia Opiz., kitchen mint via $\mathrm{ZnSO}_{4}$ biofortification during plantation. FFHD J 2016, 6: 279-290.

33. Oh MM, Carey EE, Rajashekar CB: Environmental stresses induce health-promoting phytochemicals in lettuce. Plant Phys Biochem 2009, 47:578-583.

34. Ramakrishna A, Ravishankar GA: Influence of abiotic stress signals on secondary metabolites in plants. Plant Signal Behav 2011, 6:1720-1731.

35. Świeca M: Elicitation with abiotic stresses improves pro-health constituents, antioxidant potential and nutritional quality of lentil sprouts. Saudi J Biol Sci 2015, 22:409-416.

36. Sharma P, Jha AB, Dubey RS, Pessarakli M: Reactive oxygen species, oxidative damage, and antioxidative defense mechanism in plants under stressful conditions. $\mathrm{J}$ Bot 2012, 26

37. Pusztahelyi T, Holb I, Pócsi I: Secondary metabolites in fungus-plant interactions. Front Plant Sci 2015, 6 (573)

38. Konczak I, Zhang W: Anthocyanins - more than nature's colours. J Biomed Biotechnol 2004, 5:239-240.

39. Glover BJ, Martin C: Anthocyanins. Curr Biol 2012, 22:147-150.

40. Eckardt NA: A new chlorophyll degradation pathway. The Plant Cell 2009, 21:700.

41. Hörtensteiner S, Kräutler B: Chlorophyll breakdown in higher plants. Biochim Biophys Acta 2011, 1807:977-988.

42. Steyn WJ, Wand SJE, Holcroft DM, Jacobs G: Anthocyanins in vegetative tissues: a proposed unified function in photoprotection. New Phytol 2002, 155:349-361.

43. Zhang Q, Su LJ, Chen JW, Zeng XQ, Sun BY, Peng CL: The antioxidative role of anthocyanins in Arabidopsis under high-irradiance. Biol Planta 2012, 56:97-104.

44. Ueno O, Bang SW, Wada Y, Kondo A, Ishihara K, Kaneko Y, Matsuzawa Y: Structural and biochemical dissection of photorespiration in hybrids differing in genome constitution between Diplotaxis tenuifolia $(\mathrm{C}(3)-\mathrm{C}(4))$ and radish $(\mathrm{C}(3))$. Plant Physiol 2003, 132:1550-1559.

45. Schlüter U, Bräutigam A, Gowik U, Melzer M, Christin PA, Kurz S, Mettler-Altmann T, Weber APM: Photosynthesis in C3-C4 intermediate Moricandia species. J Exp Bot 2017, 68:191-206.

46. Bao J, Cai Y, Sun M, Wang G, Corke H: Anthocyanins, flavonols, and free radical scavenging activity of chinese bayberry (Myrica rubra) extracts and their color properties and stability. J Agric Food Chem 2005, 53:2327-2332.

47. Seo WD, Kim JY, Han SI, Ra JE, Lee JH, Song YC, Park MJ, Kang HW, Oh SK, Jang KC: Relationship of radical scavenging activities and anthocyanin contents in the 12 colored rice varieties in Korea. J Korean Soc Appl Biol Chem 2011, 54:693699.

48. Jhin C, Hwang KT: Prediction of radical scavenging activities of anthocyanins applying adaptive neuro-fuzzy inference system (ANFIS) with quantum chemical descriptors. Int J Mol Sci 2014, 15:14715-14727. 
49. Pasini F, Verardo V, Caboni MF, D'Antuono LF: Determination of glucosinolates and phenolic compounds in rocket salad by HPLC-DAD-MS: Evaluation of Eruca sativa Mill. and Diplotaxis tenuifolia L. genetic resources. Food Chem 2012, 133:10251033.

50. Chacko SM, Thambi PT, Kuttan R, Nishigaki I: Beneficial effects of green tea: A literature review. Chin Med 2010, 5:13-13.

51. Lorenzo JM, Munekata PES: Phenolic compounds of green tea: Health benefits and technological application in food. Asian Pac J Trop Biomed 2016, 6:709-719.

52. Renaud S, Ruf JC: The French paradox: vegetables or wine. Circ 1994, 90:3118.

53. Sale S, Tunstall RG, Ruparelia KC, Potter GA, Steward WP, Gescher AJ: Comparison of the effects of the chemopreventive agent resveratrol and its synthetic analog trans 3,4,5,4'-tetramethoxystilbene (DMU-212) on adenoma development in the ApcMin+ mouse and cyclooxygenase- 2 in human-derived colon cancer cells. Int $\mathbf{J}$ Cancer 2005, 115:194-201.

54. Dominique D, Allan L, Didier C, Brigitte J, Norbert L: Resveratrol as a chemopreventive agent: A promising molecule for fighting cancer. Curr Drug Targets 2006, 7:423-442.

55. Athar M, Back JH, Tang X, Kim KH, Kopelovich L, Bickers DR, Kim AL: Resveratrol: A review of pre-clinical studies for human cancer prevention. Toxicol App Pharmacol 2007, 224:274-283.

56. Baur JA, Sinclair DA: Therapeutic potential of resveratrol: the in vivo evidence. Nat Rev Drug Discov 2006, 5:493-506.

57. Patel KR, Brown VA, Jones DJL, Britton RG, Hemingway D, Miller AS, West KP, Booth TD, Perloff M, Crowell JA, Brenner DE, Steward WP, Gescher AJ, Brown K: Clinical pharmacology of resveratrol and its metabolites in colorectal cancer patients. Cancer Res 2010, 70:7392-7399.

58. Smoliga JM, Blanchard O: Enhancing the Delivery of Resveratrol in Humans:If Low Bioavailability is the Problem, What is the Solution? Molecules 2014, 19:1715417172.

59. Johnson JJ, Nihal M, Siddiqui IA, Scarlett CO, Bailey HH, Mukhtar H, Ahmad N: Enhancing the bioavailability of resveratrol by combining it with piperine. Mol Nutr Food Res 2011, 55:1169-1176.

60. Martínez-Sánchez A, Gil-Izquierdo A, Gil MI, Ferreres F: A comparative study of flavonoid compounds, vitamin $\mathrm{C}$, and antioxidant properties of baby leaf Brassicaceae species. J Agri Food Chem 2008, 56:2330-2340.

61. Habu JB, Ibeh BO: In vitro antioxidant capacity and free radical scavenging evaluation of active metabolite constituents of Newbouldia laevis ethanolic leaf extract. Biol Res 2015, 48:16.

62. Lobo V, Patil A, Phatak A, Chandra N: Free radicals, antioxidants and functional foods: Impact on human health. Pharmacog Rev 2010, 4:118-126.

63. Nimse SB, Pal D: Free radicals, natural antioxidants, and their reaction mechanisms. RSC Adv 2015, 5:27986-28006.

64. Apak R, Güçlü K, Özyürek M, Çelik SE: Mechanism of antioxidant capacity assays and the CUPRAC (cupric ion reducing antioxidant capacity) assay. Microchim Acta 2008, 160:413-419. 